\title{
Rare Presentations of Metastatic Renal Cell Carcinoma with Hematochezia and Anemia
}

\author{
Janki Patel*1, Niraj Patel ${ }^{2}$ and Denise Kalmaz ${ }^{1}$ \\ ${ }^{1}$ Division of Gastroenterology, Department of Medicine, University of California at San Diego, USA \\ ${ }^{2}$ Division of Gastroenterology, Kaiser Permanente Baldwin Park Medical Center, USA
}

Received: 眥 July 21, 2018; Published: 㱕 August 03, 2018

*Corresponding author: Janki Patel, MD, UC San Diego, Division of Gastroenterology, 9500 Gilman Drive, \#0956, La Jolla CA 920930956

Keywords: Carcinoma; Cancer; Endoscopy; Hemoglobin

Abbreviations: RCC: Renal Cell Carcinoma; CT: Computed Tomography; EGD: Esophago-Gastroduodenoscopy

\section{Introduction}

Renal cell carcinoma (RCC) is the sixth most common cancer in men and the eighth most common cancer in women in the United States, with an estimated 65,150 new cases diagnosed in 2013 [1]. RCC's classic presenting triad of hematuria, flank pain and palpable abdominal mass are only present in about 9 percent of patients and often, RCC is found incidentally on imaging. At diagnosis, about $16 \%$ of cases have evidence of disease in lymph nodes and 16\% with distant metastases [2]. Typical sites for metastasis include lungs, bone, liver, and brain, [3] whereas intestinal metastasis is rare [4]. It is important for gastroenterologists to acknowledge the possibility of presence of metastases during endoscopy in these patients. In this case series, we present three patients with history of renal cell carcinoma with gastrointestinal metastases.

\section{Case Report}

\section{Patient 1}

A 52-year-old male with HIV and new onset iron deficiency anemia presented for further evaluation of acute blood loss anemia with hemoglobin decrease from 16 to $7.9 \mathrm{mg} / \mathrm{dl}$. Six months prior to presentation, he had EGD with LA Class B esophagitis and colonoscopy with $2 \mathrm{~mm}$ sigmoid polyp (biopsy with tubular adenoma). Video Capsule endoscopy showed an ulcerated lesion in distal ileum with active oozing (Figure 1A) and a non-bleeding arteriovenous malformation (Figure1B). A $1.5 \mathrm{~cm}$ ulcerated distal ileum lesion was discovered on single balloon enteroscopy subsequently with biopsy revealing metastatic carcinoma with clear cell phenotype, with immunohistochemistry consistent with primary renal cell carcinoma. A new diagnosis of metastatic RCC was made by single balloon enteroscopy.

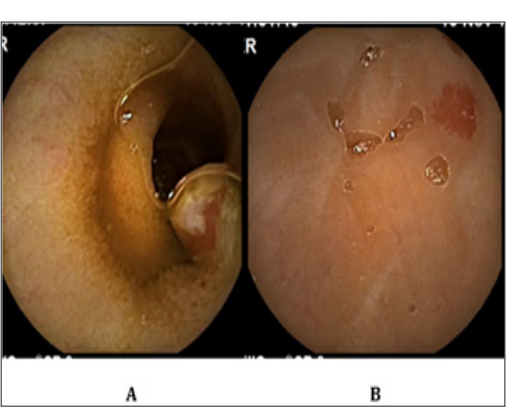

Figure 1: A: Video Capsule Endoscopy images with ulcerated lesion in distal ileum with active oozing, B: nonbleeding arteriovenous malformation.

\section{Patient 2}

A 54-year-old male with history of stage 1 clear cell RCC status post right nephrectomy 3.5 years prior, presented to the emergency room with hematochezia, anemia, and chest pain. The patient developed painless hematochezia 6 months prior to admission and had a colonoscopy performed outside of the United States three months prior to admission, which was reportedly normal. He was diagnosed with non-ST elevation myocardial infarction and underwent a left heart catheterization that showed multivessel coronary artery disease. After starting dual anti-platelet therapy with aspirin and clopidogrel, he had frank hematochezia and worsening anemia. An abdominal computed tomography (CT) scan revealed a soft tissue mass in the right nephrectomy surgical bed measuring $3.2 \mathrm{~cm} \times 3.7 \mathrm{~cm}$, innumerable lesions within the left kidney, left adrenal mass, multiple pulmonary nodules and 
lymphadenopathy consistent with metastatic disease but the colon was noted to be unremarkable. A push enteroscopy and colonoscopy were performed for ongoing intermittent hematochezia. The enteroscope was advanced to approximately $40 \mathrm{~cm}$ past the ligament of treitz and examination was entirely normal. The colonoscopy revealed an ulcerated $1.5 \mathrm{~cm}$ pedunculated mass lesion $35 \mathrm{~cm}$ from the anal verge (Figure 2A) with biopsies consistent with clear cell RCC (Figure 2B \&1C).



Figure 2: A: $1.5 \mathrm{~cm}$ pedunculated, lesion was found in the sigmoid colon, $35 \mathrm{~cm}$ from the anal verge. The lesion had an $8 \mathrm{~mm}$ eschar over an area of ulceration without active bleeding. B: H\&E staining: Large cells with clear cytoplasm are seen which is characteristic of clear cell RCC C: CD10 staining: CD10 is typically expressed on the brush border of renal tubular cells. Positive staining here indicates the renal origin of the cells.

\section{Patient 3}

A 62-year-old male with known metastatic renal cell carcinoma presented with anemia and hematochezia. Patient had a CT scan of abdomen/pelvis performed prior to admission which revealed an ill-defined mass at the upper pole of the right kidney measuring $5.8 \mathrm{~cm} \times 4.5 \mathrm{~cm}$ but small and large bowel were reported as unremarkable. An esophagogastroduodenoscopy (EGD) did not identify a source of bleeding and a colonoscopy showed blood present throughout colon and terminal ileum without a clear source of bleeding. On following day, repeat colonoscopy revealed blood throughout colon and melena in terminal ileum. Video Capsule endoscopy showed a small clot in proximal jejunum. A push enteroscopy was then pursued, which revealed a $1.2 \mathrm{~cm}$ round polypoid lesion in the proximal jejunum occupying one-third of bowel lumen (Figure 3A \& 3B). Metastatic renal cell carcinoma lesions were confirmed with biopsies.

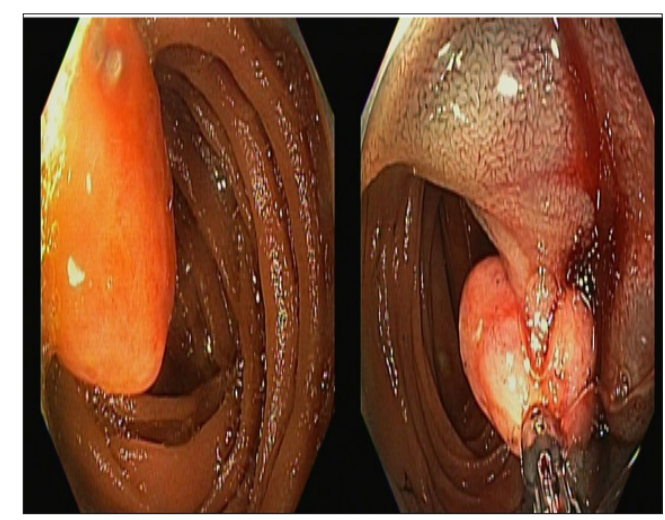

Figure 3: A: Push enteroscopy images with $1.2 \mathrm{~cm}$ nodular polypoid lesion B: Circumferential lesion occupying onethird of bowel lumen.

\section{Discussion}

At presentation, $20-30 \%$ of the patients with RCC have metastatic disease. Prognosis for patients with Stage IV RCC is poor with median survival of only 10-15 months compared to patients with Stage I RCC who have a 5-year survival rate of $80-95 \%$ [5]. RCC often metastasizes to lungs, bone, brain, renal fossa and liver. Although metastatic RCC is common, intestinal metastases from RCC are rare and often only reported in case reports [6,7]. Intestinal metastasis from renal cancers often present as hemorrhage, bowel intussusception, bowel obstruction due to luminal occlusion, or rarely as perforation. In the cases presented here, the patients presented with hematochezia or anemia secondary to renal cancer metastases to the small intestines and colon. In two of the patients, capsule endoscopy was key in making the diagnosis of metastatic disease in the small bowel. Given the possibility of intestinal metastases in renal cancers, careful endoscopic evaluation should be performed in patients with RCC presenting with new symptoms of gastrointestinal bleeding or abdominal pain.

\section{References}

1. Siegel R, Naishadham D, Jemal A (2013) Cancer statistics. CA Cancer J Clin 63(1):11-30.

2. Howlader N NA, Krapcho M, Miller D, Bishop K, Altekruse SF, et al. (2015) SEER Cancer Statistics Review. Bethesda, MD: National Cancer Institute.

3. Ljungberg B, Alamdari FI, Rasmuson T, Roos G (1999) Follow-up guidelines for nonmetastatic renal cell carcinoma based on the occurrence of metastases after radical nephrectomy. BJU Int 84(4): 405411.

4. Jadav AM, Thrumurthy SG, DeSousa BA (2010) Solitary colonic metastasis from renal cell carcinoma presenting as a surgical emergency nine years post-nephrectomy. World J Surg Oncol 8: 54.

5. Elmore JM, Kadesky KT, Koeneman KS, Sagalowsky AI (2003) Reassessment of the 1997 TNM classification system for renal cell carcinoma. Cancer 98(11): 2329-2334. 
6. Milovic N, Lazic M, Aleksic P, Radovanović D, Bancević V, et al. (2013) Rare locations of metastastatic renal cell carcinoma: a presentation of three cases. Vojnosanit Pregl 70(9): 881-886.
7. Chawla A, Mishra D, Bansal R, Chundru M (2013) Rare sites of delayed metastasis in renal cell carcinoma. BMJ Case Rep.
ISSN: 2574-1241

DOI: 10.26717/BJSTR.2018.07.001529

Janki Patel. Biomed J Sci \& Tech Res



Submission Link: https://biomedres.us/submit-manuscript.php

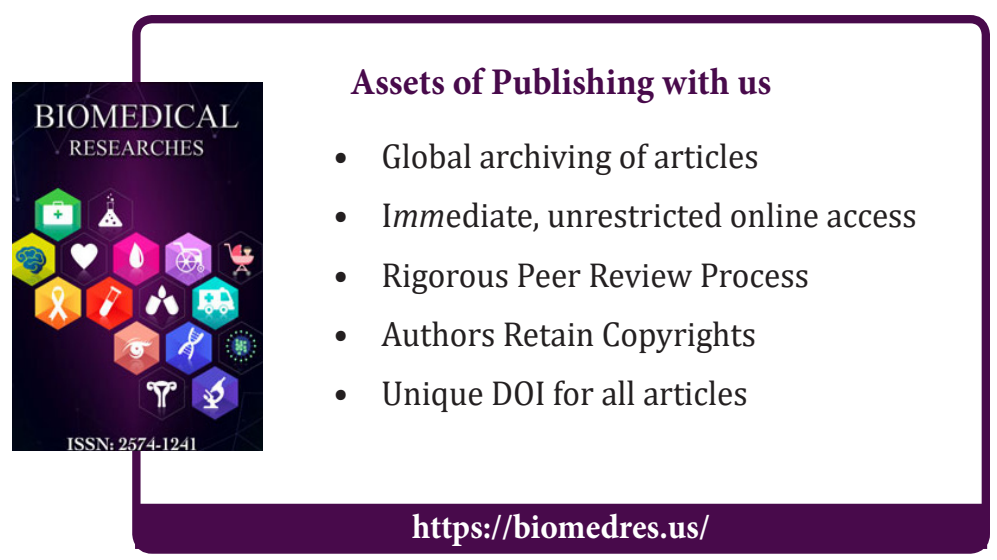

